\title{
Knowledge versus content in e-learning: A philosophical discussion
}

\author{
Gonçalo Jorge Morais Costa • Nuno Sotero Alves Silva
}

(C) Springer Science + Business Media, LLC 2009

\begin{abstract}
Historically education has been supported by technology; however, during the past three decades electronic technologies for educational purposes have been used to achieve better learning outcomes. There are two propositions regarding the use of computers for educational purposes; that is, people can learn "from" technologies or people can learn "with" technologies. The, e-learning literature reveals that technological and instructional perceptions are diffuse. Furthermore, only recently have the ethical and cultural issues been considered. The philosophical discussion within this paper considers these issues and explores the idea of knowledge or content in e-learning, teasing out the differences between these two concepts. In order to contextualize the debate, the literature is reviewed, and a philosophical debate using an inquiry example is presented.
\end{abstract}

Keywords E-learning · Knowledge - Content · Philosophical argument

$\begin{array}{ll}\text { Abbreviations } \\ \text { CDA } & \text { Content Delivery Application } \\ \text { CM } & \text { Content Management } \\ \text { CMA } & \text { Content Management Application }\end{array}$

This paper is an enhanced and revised version of the paper presented during ETHICOMP 2008.

\footnotetext{
G. J. M. Costa $(\bowtie) \cdot$ N. S. A. Silva

Centre for Computing and Social Responsibility,

De Montfort University,

Leicester, UK

e-mail: goncaloj@netc.pt

N. S. A. Silva

e-mail: nsas@lis.ulusiada.pt
}

$\begin{array}{ll}\text { CMS } & \text { Content Management Systems } \\ \text { CoCM } & \text { Conceptual Content Management } \\ \text { CuCM } & \text { Cultural Content Management } \\ \text { GCM } & \text { Global Content Management } \\ \text { KM } & \text { Knowledge Management } \\ \text { KMS } & \text { Knowledge Management Systems } \\ \text { LCMS } & \text { Learning Content Management Systems } \\ \text { LKMS } & \text { Learning Knowldge Management Systems } \\ \text { LMS } & \text { Learning Management Systems } \\ \text { LO } & \text { Learning Objects } \\ \text { LOKMS } & \text { Learning Objects Knowledge Management } \\ & \text { Systems } \\ \text { MLE } & \text { Managing Learning Environment } \\ \text { PCM } & \text { Personal Content Management } \\ \text { PKM } & \text { Personal Knowledge Management } \\ \text { PLEs } & \text { Personal Learning Environments } \\ \text { SS } & \text { Social Software } \\ \text { VLE } & \text { Virtual Learning Environments }\end{array}$

\section{Introduction}

The radical technological change of the past three decades has enhanced the importance of technology within the educational process. Many studies have been conducted to scrutinize interactive learning technologies in a multiplicity of forms, ranging from the earliest days of mainframe-based computers to modern multimedia learning environments, with accessibility via the Internet (Reeves 1999). It is possible to recognise two main propositions concerning the use of computers for educational purposes; people can learn "from" technologies or people can learn "with" technologies. Jonassen and Carr (2000) argue that when computer technologies are used to deliver pre-programmed instruc- 
tional lessons, they should be referred to as interactive technologies.

In this educational paradigm, learners merely obtain knowledge through the use of technologies as a vehicle. Technologies are considered as forms of "media" which are conveyors of information, using a computer network to present or distribute some educational content (Keegan 1988). So, learners are unreservedly regarded as the recipients of encoded knowledge in assorted forms of instructional media (Jonassen and Reeves 1996). In this approach, learning "from" technologies is passive and limited to entering responses and getting replies from them.

On the other hand, learning "with" interactive technologies establishes a certain intellectual affiliation between learners and technologies. Instead of using technologies to guide learners through prearranged interactions, learners may use technologies that function as "the mindful engagement of learners". When students learn with computer technologies, instead of being restricted by them, they increase their level of engagement (Jonassen and Carr 2000; de Byl 2007; Small and Vorgan 2008).

Crump and Costea (2003) suggest that these different types of learning using technology exist on a dynamic continuum. Furthermore, they are influenced by cultural and ethical differences. For example, if a culture does not recognise, encourage, or reward learning sharing, this is the end of knowledge management (KM) (Sarah and Haslett 2003). Nonaka et al. (2001, pp. 828) claim that knowledge is fragile, and depends on beliefs and commitment, "knowledge-creation is a dynamic human process of justifying a personal belief directed towards the truth". According to Anderson (2004), the learning environment should respect and accommodate particular cultural attributes, especially language and particular forms of expression, which the learner uses to interpret and build knowledge. Such claims can be combined with Hofstede's work (1986, pp. 306): "the focus of the teacher's training should be on learning about his/her own culture, getting intellectually or emotionally accustomed to the fact that in other societies, people learn in different ways".

The relationship of ethics and learning using technologies is complex (Jefferies and Stahl 2005). In order to achieve a responsible use of technology for learning, the participants need a considerable amount of education, referring to established as well as the ethical norms (Stahl 2002a).

In this paper learning using technology, regardless of whether it is a "from" or "with" perspective will be termed e-learning.

E-learning comprises several hierarchical layers as described in the framework in Fig. 1 by Silva (2007). Throughout these layers there is an interrelationship between culture and ethics. Indeed, these are the items which make a difference amongst the particular e-learning offerings. This paper focuses upon the knowledge/content management layer, which is a fundamental layer in delivering effective e-learning.

It is interesting that e-learning literature seems to pay little regard to this notion of $\mathrm{KM}$ and content management $(\mathrm{CM})$, not considering the differences and similarities between concepts of knowledge versus content. There is some implied consideration (see, for example, Wilson et al. 1987; Ball and McDiarmid 1990; Rowan et al. 2001; Mulhall et al. 2003; Bucat 2004; Kanuka 2006; McRobb et al. 2007; Cavin 2008; Koppelman 2008), which suggests that successful teachers cannot simply have an intuitive or personal understanding of a particular concept, principle, or theory. Rather, they must themselves understand ways of representing the concepts to students, which leads to the concept of pedagogic content knowledge.

Richards (2004) suggests that e-learning is globally accepted as a prerequisite for future social and economic development, providing a new essential style, which in turn is the base level for accessible education.

Against this backdrop, the paper considers the notions of knowledge and content in an e-learning setting. Furthermore, the paper discusses: the concept of e-learning; defining knowledge; KM; KM Systems
Fig. 1 The e-University strategic implementation conceptual framework (Silva 2007)

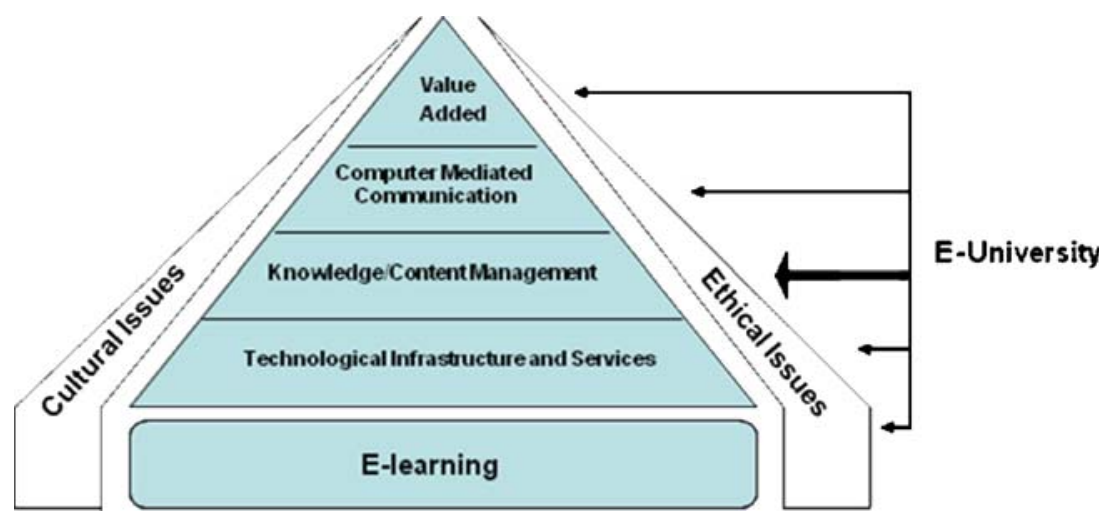


(KMS); the link between $\mathrm{KM}$ and e-learning; defining content; CM Systems (CMS); the link between CM and e-learning; and, finally, the philosophical argument using an enquiry example which draws the previous discussions together.

\section{Development}

\subsection{E-learning}

The literature addressing the concept of e-learning is vast and rich. We support the following assertions : "e-learning is nothing more than the use of electronic tools and technologies to assist us in our teaching and learning" (Martin and Webb 2001, pp. 15); "e-learning will here be defined as the use of ICT in higher education, which aims mainly the independent use of technology by students" (Stahl 2005, pp. 21); and finally, e-learning can be defined as the online delivery of information for purposes of education, training, or KM, and is different from formal education, which occurs off campus, and usually, but not always, through online resources (distance learning) (Turban et al. 2006).

From a review of the e-learning literature, four general categories of e-learning technological systems can be discerned:

- Learning Management Systems (LMS)- support administrative tasks such as registration, scheduling, and learner tracking (Sigrén and Holmqvist 2005; Bongalos et al. 2006; Lassila and Poyry 2007);

- Managed Learning Environment (MLE)- includes the whole range of information systems and processes, which contribute directly or indirectly to learning and learning management (JISC 2000; Winter 2006);

- Learning Content Management Systems (LCMS)- allow developers to store, manage and provide access to pieces of content used in e-learning (Podoleanu 2005; Jurubescu 2008; Abazi-Bexheti 2008);

- Virtual Learning Environments (VLE)- the components in which learners and tutors participate in several online interactions, including on-line learning (JISC 2000; Jenkins et al. 2005; Weller 2007).

So, the key elements in an e-learning project are: lecturer, content, student, place, time and interactivity (Amaral and Leal 2004). However, an important question arises: what are the defining characteristics of "good" elearning? Following Hall (2003) and Turban et al. (2006), the inputs for effective e-learning are:

- visual- when appropriate, uses relevant images, video, audio, and other media, rather than simply text, providing information to learners;
- concise- written information should be concise, because is an important element of e-learning;

- interactive- learners can interact with the courseware through quizzes and multimedia activities, allowing them to practice their skills, demonstrate knowledge, discover relationships and new information, and reinforce learning;

- engaging- appeals to learners' professional experience and emotions;

- relevant- should address learners' current needs or learning gaps;

- feasible- the technological infrastructure for enabling elearning should be feasible for learners';

- empowering- providing access to additional resources may allow self-directed learners to explore material relevant to their interests, achieving a better and more complete knowledge.

Therefore, an e-learning process comprises conceptual and physical components and procedures that should be standardized in terms of both procedures and technologies. Development, through the whole lifecycle of the e-learning process, must be done on the basis of widely adopted standards (Lytras and Sicilia 2005). As far as the conceptual background of an e-learning application is concerned, the following issues must be well defined:

e-learning process design;

learners' competencies definition;

- a framework for co-operation amongst teachers and pupils, within which, the physical components comprise: learning content and its packaging and deployment; learners' profile; assessment activities; metadata structure; system architecture.

In conclusion, the quoted references do not recognize conceptual differences between $\mathrm{KM}$ and $\mathrm{CM}$ in an elearning project, which once again entails the need for this paper.

\subsection{Defining knowledge}

According to Plato, knowledge is justified true belief. In "Protagoras", Plato argues that "knowledge is the food of the soul" (Jowett 1899). Moreover, the Oxford Dictionary (2008) defines knowledge as a result or product of knowing; information or understanding acquired through experience; practical ability or skill; cognition. These wider definitions can be more refined given the aim of this paper. Standards Australia (2003) provides a definition of knowledge as a body of understanding and skills which is constructed by people. Knowledge increases through interaction (typically from other people). For Awad and Ghaziri (2004), knowledge encompasses the understanding 
obtained through the process of experience or appropriate study. Or still, Kuhn (1970) claims that knowledge is an individual construction regarding a current context (community), rather than representing some correspondence to external reality.

At this point, we need to clarify the conceptual distinctions concerning data, information, knowledge, and wisdom. Data can be defined as isolated facts, non structured representations (Carvalho and Amaral 1993), which can be pertinent or not in specific circumstances (Alter 1996). Information is explained by Buckland (1991), as a thing; instead, information can be seen as a "basic material" that will be used by manufacturing during the "production stage" (Cash et al. 1992), or a precious fluid (Kornai 2008) that contains a high level of semantics and less mathematical construction (Himma 2005). However, Foskett's (1977) challenging distinction between knowledge and information is very useful to our purpose: knowledge is what I know, information is what we know. Finally, it is necessary to understand that data, information, knowledge and wisdom can be viewed as part of a continuum, one leading into another; each one resulting from the previous actions, with no clear boundaries between them.

Stacey (2001) draws attention to the paradoxical nature of knowledge, which is at the same time: a thing and a flow or a process. He emphasizes that we have to observe their combination and not each one separately. Furthermore, Stacey points out some key heuristic features: knowledge can only be volunteered and "we only know what we know when we want to know it", referring to the value of narrative.

Knowledge is embedded - it is what we would call "justin-context". This means that it is specific to time, place, sequence, timing, position, and relationships, within communities' contextualization. Furthermore, it follows that knowledge cannot be abstracted from context, physical or social. Snowden (2000) acknowledged that, to manage knowledge we need to focus more on context and speech, than on content. Regarding e-learning or distributed learning, the importance lies in the possible restriction to learning, given the abstracted information process, and considering the implied knowledge. Learners need to develop their own knowledge, through a learning process which should include information on procedure, but relating different contexts.

\subsection{Knowledge management}

The concept of KM was first coined in the 1980's, with the aim off not reinventing the wheel in organizational contexts. Later, the focus shifted to the best use of knowledge concerning customers. The current phase of
$\mathrm{KM}$ is interactive web based $\mathrm{KM}$, leading to a unanimously accepted definition of KM.

The crux of KM is unwinding and sharing knowledge throughout the organization to leverage competitive advantage. We need to distinguish two types of knowledge: tacit knowledge and explicit knowledge. These knowledge classifications are the most common key features in KM. Explicit knowledge is formal knowledge, which can be articulated and transferred easily to others. It includes policies, procedures, theories, facts, etc. Tacit knowledge or implicit knowledge is informal knowledge, which is deeply rooted in a person's mind. It is such personalization that makes it difficult to formalize, communicate or transmit to others. Therefore, KM leads to the following processes: knowledge acquisition, knowledge elicitation, knowledge organization and representation, knowledge transfer, distribution and knowledge retrieval.

Given KM characteristics its key features are: people, content, culture, process, and technology (Phillips 2000). People are the ones that produce, use and share knowledge; a culture of sharing is crucial to the success of $\mathrm{KM}$ and Internet based learning. The KM principles if applied to education management will enhance the quality of the academic learning process. The term is used to describe everything from the application of new technology to harnessing of the intellectual capital of an organization (Sallis and Jones 2002).

Rowley (1998) describes it as follows: KM is concerned with the exploitation and development of knowledge assets in an organization, with a view to furthering organizational objectives. The knowledge to be managed includes both explicit, documented knowledge, and tacit, subjective knowledge. Management entails all of those processes associated with the identification, sharing, and creation of knowledge. It is certainly true that such preeminent issues go far beyond the infrastructure of an information system (King et al. 2002). Several frameworks of organizational learning have been suggested (Eisenhardt and Martin 2000; Zollo and Winter 2002; Akgun et al. 2003; King 2005) to stress improved levels of organizational performance.

In conclusion, $\mathrm{KM}$ emerged as a recognizable field of practice resulting from a practitioner-based response to three important social and economic trends: globalisation, ubiquitous computing and the shift towards a knowledgecentric organizational' view (Prusack 2001).

\subsection{Knowledge management systems}

KMS are technologies that support KM (knowledge generation, modification and transfer) in organizations (Marwick 2001). The use of KM in organizations is now widely recognized and expected to be an important component of organizational practices (Gartner Group 
2002). Moreover, in a 2000 survey on KM practices (KPMG 2000) 81\% of the surveyed companies engaged in some KM practices or initiatives, all using technology to support them.

However, we should note that such practices or initiatives may present different outcomes, depending on KM's technological generation. According to Marwick (2001), the first generation focused on the quest for technologies that could support the development of learning communities, and so, technologies capable of supporting threaded and synchronous discussions, and collaborative software. Second generation technologies shifted their attention to the enhancement of organizational knowledge (Malhotra 2001).

Given the above, KMS is an emerging stream of research, and several writers have provided general explanations of KMS to lead future research (Alavi and Leidner 2001; Dilnutt 2002; Leech and Sutton 2002). Moreover, in an effort to detail specific features and functionalities, these writers have acknowledged several quandaries in organizational KMS use (Alavi 1997; Baird et al. 1997; Wickramasinghe and Mills 2002). Finally, a small number of studies have started to develop theory regarding the design of KMS and its features (Markus et al. 2002; Poston and Speier 2005). Although the emerging KMS literature has speculated about the knowledge transfer related to KMS, the need for empirical studies is still a reality (Grover and Davenport 2001; Alavi and Leidner 2001).

Finally, literature on intelligent decision supporting tools has examined knowledge acquisition and the impact of these decision supporting tools. Eining and Dorr (1991) were pioneers in this research field, but more recent research has been undertaken (see for example: Rose and Wolfe 2000; Mascha 2001; Brody et al. 2003; Smedley and Sutton 2004; Rose 2005).

2.5 The link between knowledge management and E-learning

Understanding how to structure learning experiences with specific consideration for engagement, social context, and conditions, is the core for new learning styles (Reynolds 1997). Expanding traditional definitions of literacy and learning methods into "immersion-centred" experiences of interaction with information and on-line communities is essential to prepare ourselves to participate in postindustrial society. Three forms of expression are shaping the emergence of distributed learning as a new pedagogical approach: knowledge webs complement experts, texts, libraries, and archives as sources of information; interactions in virtual communities that complement face-to-face relationships in teams and classrooms; immersive experi- ences in shared internet environments allowing extend learning experiences in real world settings.

In spite of the separate evolution of KM and e-learning, the truth is that recent evidence demonstrates a convergence of these two fields of research (Efimova and Swaak 2002; Mason 2005; Mihalca et al. 2008). This convergence is characterized by a mutual feedback process that entails into two levels of analysis:

- the influence of e-learning on KM processes- the desired outcome for learning should be knowledge acquisition and a combination with some practical skills gained throughout the educational process which must represent some type of competence. Therefore, communication and collaborative work must be improved and free exchange of competencies provided;

- e-learning and KM common characteristics- collaboration is an extremely critical process for both activities. Means for communication and collaboration are one of the most important characteristics of successful education and team work. They could include synchronous and asynchronous communication and different tools, e.g., chats, discussion forums, and faqs, related to work in groups from different types of virtual communities, which encompasses informal training. Plus, free exchange of knowledge and data as well as capabilities for collaborative editing of documents become even more critical when different members have different geographical locations. Given the above, there is a strong tendency to see informal and formal learning as separate. Informal learning embodies everyday practices, horizontal knowledge and non-educational settings. Formal learning is characterized by acquisitional and individual learning, vertical or propositional knowledge (Askew 2007).

All efforts to implement e-learning will eventually move towards the total automation of teaching, learning and management processes- Learning Management Systems (LMS). For Siemens (2004), LMS are often viewed as a starting point (or critical component) of any e-learning or blended learning program. This perspective is legitimate from a management and control standpoint, but antithetical considering the way most people learn today.

Learning Circuits points out the following common features in a LMS (Learning Circuits 2002):

- they are the support for blended learning when classroom and virtual learning are synergized, aiming at prescriptive and personalized training;

- they allow integration with the human resource department, enabling automatic update of staff profiles;

- they include management tools to enable registration, updating of profiles, curricula setting, tutor assign- 
ments, courses planning and execution, internal budget contents and administration, timetables scheduling, user payments and refunds and individual and group performance production;

- they have content integration, providing native support for a diverse range of third-party courseware;

- they include compliance with learning standards such as SCORM and AICC;

- they use assessment tools to enable evaluation of a programme, course or lesson over time;

- they assess and identify training needs and management skills, using them as a resource;

- they can easily be configure with third-party systems.

Therefore, the evolution of LMS engages two different concepts (Hall et al. 2003):

- Learning KM Systems (LKMS)- LMS evolution due to social interaction, which entails Personal Learning Environments (PLEs) and Social Software (SS);

- Learning Oriented KM Systems (LOKMS)- LMS evolution at an instructional level.

PLEs are a recent feature of LKMS, as an alternative to the structured model of an LMS. PLEs are defined as: "systems that help learners to take control and manage their own learning" (van Harmelen 2006, pp. 1). Therefore, PLEs encompass self-organised learning networks as a basis for education, that go beyond course and curriculum centric models, embodying a learner-centred and learner controlled model for lifelong learning (Wild et al. 2008). SS is "a conceptual shift that acknowledges the reality of distributed learning practices and the range of learner preferences" (Fraser 2006, pp. 9). A variety of informal, socially-based tools comprise concepts such as the following: blogs, wikis, social bookmarking sites, social networking sites, content aggregation through RSS or Atom, integrated tools, podcast and video cast tools, search engines, email, and voice over IP (Dalsgaard 2006; Karrer 2007; Chatti et al. 2007).

The other theoretical approach was first developed by Hall and Paradice (2005), and later refined to include feedback loops concerning KMS underlying inquiring systems. The result combines the flexibility of inquiring systems with an enhanced version of Simon's IntelligenceDesign-Choice model to form a conceptual LOKMS for inquiring organizations. Loops that provide feedback and time/space analysis on the desired state/current state potential gap are evident throughout the system. The system contains modules and components that facilitate organizational decision-making and memory enhancement. The LOKMS for inquiring organizations places much of its energy in the intelligence phase. Both proactive and reactive information acquisition occurs during this phase, as does problem definition.

\subsection{Defining content}

According to etymological analysis, content is defined as: “contained, satisfied, or still the contented person's desires, being bound to what he or she already has" (Online Etymology Dictionary 2001). Or, "something contained as in a receptacle, being also the meaning or significance of a literary or artistic work" (The Free Dictionary 2008).

Moreover, such conceptualizations allow us to argue that content has three major characteristics:

- can be the text matter of a document or a publication in any form;

- is the essence of a communicated message or speech, as comprehended or received by its intended audience;

- is the "glue" that makes a website "sticky".

The later characteristic refers to content in a digital sense, and according to the OECD (2008) such content is becoming a more significant ingredient in OECD economies, being delivered by numerous stakeholders:

- content/entertainment industries- whose primary activity is the production and sale of physical or digital content;

industries- that are not content industries per se, but which increasingly produce digital content as secondary activities;

governmental- government activities in areas such as research, education, health and culture;

- users- content created by network users.

Clearly, it becomes necessary to make the first argument concerning the difference between knowledge and content. Budin (2002), in a modest attempt at distinguishing the different conceptual levels, concludes through an iterative and recursive value-adding chain that:

data + interpretation $=$ information

information + cognitive appropriation $=$ knowledge

knowledge + collective representation and utilization $=$ content.

Knowledge in order to be justifiable underpins an important condition: cognitive appropriation. Knowledge is constantly the outcome of cognitive operations, however not limited to the personal, individual or subjective level. Budin (2002) point out that content refers to any piece of information that exists within an organization. In fact, Budin argues for the following four categories concerning content:

- controlled- contents and relations which are under reconsideration control. Controlled content may be structured or unstructured; 
- uncontrolled- content that is not under amendment control. It may exist in any information storage system;

- $\quad$ structured- usually considered as data stored in databases;

- unstructured- typically refers to documents and other electronic or physical media containing the information.

Which are the characteristics of educational content? The content of education is extremely important to the future of our society, and for that reason a considerable number of content standards arise. A content standard in education is a statement that can be used to judge the quality of curriculum contents, or a component of an evaluation method (Kendall and Marzano 1997). Clearly, content standards define only the core elements of education that should apply to all students without regard to their specific career and academic plans. Every student is expected to achieve goals that are broader than those outlined by the standards. Therefore, throughout the educational process the focus shifts from the core standards (what goes into the educational system) to the results of the content standards (what comes out of the educational system).

Thus, content standards can accomplish three primary goals (InTime, 2001):

- give learners and lecturers a clear and challenging target;

- help focus energy and resources on the main purposelearners achievements;

- give a tool for evaluating how learners are learning, and how schools are performing.

However, a considerable number of communities within universities, produce, store and share miscellaneous contents ranging from syllabi and lecture notes to articles, papers, simulations or research results, stored in databases, which are used by the community members. This statement demonstrates that content must be created in accordance with the learning environment's context and needs, given the fact that, learning and resource allocation for learning, will differ among different cultures, and a pre-determination concerning design may introduce ethical issues (Richter et al. 2005). So, we will also explore the pedagogic context of such a learning environment's impact over content.

\subsection{Content management systems}

CMS have advanced from previous systems. Therefore, each system has a dependent correlation with its predecessors- a certain crucial point regarding technology and functionality. Possible precursors are document management systems, editorial process management systems, workflow management systems or database management systems (Bergstedt et al. 2003). However, the literature seems once again to reflect a blurred or incomplete conceptualization of such systems, which is illustrated by the following definitions:

- Inglis (2003, pp. 5)- “CMS are systems for reorganizing and simplifying the loading of content into websites. CMS perform a variety of functions including generating HTML pages, serving as digital repositories of information, importing information from other systems and flowing information to web pages. In higher education, CMS represent a new type of software technology for supporting the delivery of information in Web-based courses";

- Svarre (2006, pp. 1)- "A CMS is a system used to manage the content of a Web site. Typically, a CMS consists of two elements: the content management application (CMA) and the content delivery application (CDA). The CMA element allows the content manager or author, who may not know HTML, to manage the creation, modification, and removal of content from a Web site without needing the expertise of a Webmaster. The CDA element uses and compiles that information to update the Web site";

- or finally, Sehring et al. (2006)- "Conceptual Content Management (CoCM) is an approach to domain engineering that enables domain experts to define domain models, allowing both personalization for individual information needs, as well as collaboration with other experts."

Given the absence of a clear definition of CMS we argue our personal vision: CMS is a tool that enables a variety of centralized technical and (de-centralized) non technical staff to create, edit, manage and finally publish a variety of contents, whilst being constrained by a set of rules, processes and workflows that ensure a coherent and validated appearance. Thus, a CMS should engage the following features (Wilkoff et al. 2001; Antilla 2001):

- web document management- management and publishing of web contents for intranet, extranet, and internet sites. Plus, features such as library services and administration, web content management tools that specialize in content authoring, template design, and web publishing workflows;

- document management- includes document life cycle management, which means creating, editing, approving and reviewing, publishing, searching and viewing, archiving and deleting of a document;

- digital assets management- used when sites contain large amounts of rich media. Digital assets management is specialized in supporting the aggregation, storage, and indexing of rich media. 
Moreover, CMS must enable users to collaborate and interact on the creation and management of trusted content through the portal and allow users to import or create new content and edit existing content or properties. The required features must be in line with business or educational goals to be reached with the help of content management. In conclusion, features are categorised to three content management areas: creation, management and publishing, and presentation (Robertson 2002).

However, we have pointed out in the previous section that $\mathrm{CM}$ and cultural diversity determines this practice. Since the audience of any content product is always culturally bounded, content management must always take into account cultural factors in content design and all the remaining processes and tasks of content management. So, the key processes in content management are:

- design and creation of content;

- processing of content;

- presentation of content in different media and knowledge representation forms;

- dissemination of content in the several platforms (digital or physical);

- sharing content in collaborative workspaces;

- using content for diverse purposes.

Therefore, Global Content Management (GCM) must assume several dissimilar materializations (Bergstedt et al. 2003), being a component Cultural Content Management $(\mathrm{CuCM})$, encompassing the following technological features:

- cultural heritage technologies (digital libraries, digital archives and digital museums);

- e-publishing (single source methodologies);

- e-learning (managing teaching content);

- cyber science (collaborative content creation);

- digital cities and other virtual communities projects.

\subsection{The link between content management and E-learning}

In an e-learning project, content is simultaneously digital or/and physical (HP 2008); however, we will focus on digital content.

The digital content life cycle is broadly characterized by six phases: creating, updating, publishing, translating, archiving and retirement (McKeever 2003; Jervis 2008). For example, if an author or a group of authors write a paper it is content creation. Such a paper will be edited (update phase), so the editor may approve the publication (publishing phase). Providing digital access to others is also called publishing, however the same content can become outdated and removed (retiring phase) (Sehring et al. 2006).
However, this process is complex and not purely technological, because e-learning is a collaborative technology. Therefore, some basic responsibilities and roles as far as content management is concerned are necessary to address (Content Management Junction 2008; Yordanova 2008):

- content author- to create and edit content is the primary responsibility of the author. Another author responsibility is to decide the delivery style, localization and translation of the content;

- publisher- has the responsibility to publish;

- manager- the permission for accessing the content will be managed by someone. This person will also manage access to files and folders in which the content is stored;

- consumer- everyone that views the published content, however controlling the existing versions of content is not easy. To allow for version control, authors need to make content management enabling to store older version of contents as previous editions.

We should note that a recent study published by Schulmeister (2003) reveals some interesting points: content is stored as full pages or modules; didactic models are chosen when content is being created, and therefore the decision is irreversible; and also, few concepts exist, regarding quality management and support of the editorial process.

Thus, an e-learning project implementation undergoes immediate transformation regarding the role of the content developers. E-learning contents must be designed and developed in smaller manageable chunks, known as learning objects (LO) as illustrated in instructional design (Horton 2000; Shaw 2008). LOs are the small units or building blocks of instruction that can be taken as standalone units of instruction, even when it is not embedded within a larger structure of content.

Content or the content format, location and type of electronic support, assumes much more importance in elearning (Amaral and Leal 2004). In this new paradigm, content is no longer "in the lecturer", in "his brief case" or, still in "the teaching support materials", but is rather a LO, accessible 24 hours a day, 7 days a week. However, the social process of acquiring knowledge is rarely taken into consideration.

Given the above, while CMS are able to support processes and control their single steps, LMS are not able to check the learning effort of students while they use the system. So, CMS offer a feature which is urgently needed, but not yet available in LMS, because such systems can react to the change and usage of the contents present in their system.

Therefore, it is important to develop a conceptualization regarding CMS- Learning Content Management Systems (LCMS) is a term commonly used in the online publishing 
industry, whose objective is to simplify the creation and administration of online contents (articles, reports, pictures, ad banners, etc.) used in publications. This system enables the following characteristics (Brooks et al. 2006; Shaw 2007):

- $\quad$ separating content from presentation- authors need to be focused on delivering their content and not worry about layout considerations of their article (like where an image will appear), unless it is relevant to an understanding of the article;

- enforcing workflow processes- articles sent in by the authors are first approved by editors before publication. And when they are published, the articles are kept "live" for a particular period of time, after which they are backed up and archived.

\section{Philosophical argument}

So far, we have outlined the theoretical contributions that will act as boundaries for the argument; however, despite having a philosophical research question, a practical example is required to demonstrate what sort of practical problems arise from the knowledge/content management layer. The example is taken from Nuno Silva's (2007) PhD research, which uses Action Research, in order to solve the practical problems that emerged through the implementation of an e-learning project in Lusíada Universities.

To discuss the dilemma, is necessary to explain the lecturers' pedagogical choices: some simply use traditional presentations, which can be characterized as pure instructional design; others, enrich presentations adding "content" disregarding any level of standardization; finally, others use oral transmission as a pedagogical strategy and therefore have authorized digital recording of their lecturing. Despite the lecturers' different choices, attention was paid to copyright issues. However the use of collaborative tools allows debate about the presentations, which entails a process of knowledge creation and transfer that will be also stored into the e-learning platform. Such "knowledgeable files" seem to be under no category or classification, leading to a technical problem: how should the IT management department categorize such files? As knowledge or as content?

Given the previous statements, it seems clear that our philosophical debate needs to engage three levels of argument, when an e-learning project is praxis:

- ethical challenges;

- pedagogical challenges;

- the knowledge versus content focus.

Given the complexities between ethics and e-learning it is necessary to combine or aggregate professional practi- tioners and users perspectives concerning such issues. In fact, moral responsibility is transversal to all e-learning agents (technological providers, content providers, lecturers, students and support staff), leading to an important minimization of unethical practices (Nagi 2006) and because of that, it is necessary to account professional responsibility (Bynum and Rogerson 2004).

Stahl (2002a, b) identifies some moral problems (power; privacy; monitoring; surveillance; access; opportunity cost; awareness). Nevertheless, we need to pay attention to the cognitive development process that moral stages encompass (Kohlberg 1981), and naturally education plays an important role through that process. Plus, Williams (2002) and Nagi (2006) still identify other ethical problems: cheating; intellectual property; plagiarism and copyright violations; learning practices; personal integrity; and, accountability.

In spite of the fact that the evolution of E-Learning Management Systems will imply tremendous challenges, the traditional categories of content providers, lecturers and students will soon be obsolete, given the possibility of any agent to create, update, publish, translate, archive and retire and withdraw (Anderson 2004). This assumption may entail some criticism, given the role of the content manager, but this is undermined by the evolution of collaborative tools. Furthermore, such issues will enhance the debate regarding privacy as an aspect of respecting personal human rights (as claimed by Stahl 2007).

Knowledge in an e-learning environment was firstly introduced by Shulman (1988); Gudmundsdottir (1990), states that pedagogical content knowledge is a combination of subject matter knowledge and pedagogical knowledge, and these correlate, constituting teaching expertise. In this way, "content" in pedagogical content refers to subject organization. Still, in accordance to this author, lecturers need to master two types of knowledge:

- content, also known as "deep" knowledge of the subject itself;

- knowledge of the curricular development.

Content knowledge encompasses what is called the "structure of knowledge"- the theories, principles, and concepts of a particular discipline. This type of knowledge is especially important, because it deals with the teaching process, including the most useful forms of representing and communicating content and how student's best learn the specific concepts and topics of a subject. If new lecturers are to be successful, they must wrestle simultaneously with issues of pedagogical content (or knowledge), as well as general pedagogy (or generic teaching principles) (Ornstein et al. 2000). So, the pedagogical dilemma also reproduces the ambiguous distinction, and imposes an important question: can knowledge and content be different in each pedagogical theory? 
Of course, cultural needs represent a major challenge to e-learning content quality, because people inevitably speak in terms of different contexts, values and perspectives, making dialogue difficult if the same formal language is not used. Yet this is achievable since people share enough commonalities of experience and motivation to somewhat off-set cultural differences and achieve degrees of mutual understanding (Furstenberg et al. 2001). Cross-cultural dialogue is possible if people are able to reconcile what is common or similar, and what is contextually-different in human experience and practice (Clifford 1988). Another possible issue arises from curriculum requirement: if a lecturer has preferences for verbal knowledge, communication and oral discussions, with little or minimal documentation, the contents must be created with respect to the context and the needs concerning the learning and cultural environment.

Regarding the third level of argument, we acknowledge the conceptual differences between knowledge and content. Existing contributions to this debate include Gergen (1995), who explores the use of dialogue as a metaphor to evaluate a number of educational practices. In particular, he argues for knowledge as fragments of a dialogue, "knowledgeable tellings" within an ongoing relationship. This relationship can exist between learners, between a learner and a lecturer, or between a learner and an environment experienced by the learner. Gergen (1995) also describes a lecture conversation where the lecturer has already set the content, in which, the student acknowledges his arguments but does not have an opinion regarding the content delivery. Budin (2002) concludes through an iterative and recursive valueadding chain that:

data + interpretation $=$ information

information + cognitive appropriation $=$ knowledge

knowledge + collective representation and utilization $=$ content.

However, in our opinion such definitions demonstrate once again the need for this paper. Gergen's perception concerning content can be classified as reductionist, because clearly in an e-learning project learners have voice:

- the most traditional tools such as chats or, forums allow learners to express their ideas, in spite of the existence of a set of rules;

- the evolution of E-Learning Management Systems, namely PLEs offers the possibility of a truly learnercentred environment.

In addition, Gergen's view of content is similar to its etymological meaning of the concept: "something contained as in a receptacle, being also the meaning or significance of a literary or artistic work" (The Free Dictionary 2008), which means static, enclosed, inert. As we have previously stated digital content encompasses four categories that challenge or abolish such a classical definition.

Moreover, in spite of the improved perception of Budin (2002) concerning this debate, the truth is that content is not synonymous with collective knowledge representation and usage. It is inevitably tied to content quality or evaluation, because it depends on the personal knowledge and experience of both "communicational agents": the content creator and the reader. This assumption is further enhanced by the evolution of E-learning Management Systems, which enhance the need for Personal KM (PKM) and also Personal Content Management (PCM).

PKM engages the challenge of human cognition as synonymous with competency and efficacy, concerning the use of personal perception of organizational knowledge (Wright 2005; Sheridan 2008), as a recognition of the personal sharing given ba (Nonaka and Takeuchi 1995). PCM is a theoretical conceptualization that we propose, in order to demonstrate the interactive process of personal perception and evaluation concerning the four major categories of content: controlled; uncontrolled; structured; unstructured. For that, we acknowledge a similar process for PCM in accordance to the PKM $b a$ dimensional concept of the SECI model (Nonaka 1994, 2002):

content conversion- content personal perception of the e-learning agent;

- combination- if the personal perception evaluates positively such content this is combined with personal content already created;

- externalization- corresponds to the publishing of new generated content into the previous dimension;

- internalization- reflects the integration of the new produced content into the learner-centred environment, after the "audience" feedback.

Apart from content relativity, its value is also comparatively determined due to its possible weakness when compared to other contents. Plus, there is also a contextual determinism when it is delivered by experts.

Even after the presentation of the practical problem and philosophical argument the answer still remains unsolved. In order to obtain a plausible answer semantics can offer some important remarks concerning learning environments (Demetrios et al. 2004; Ronchetti and Saini 2004; Burger and Westenthaler 2006a).

According to Millard et al. (2006) semantics provides reasoning for the following realities:

- connecting communities- services that allow people to contact each other, being either proficient or learners with analogous interests; 
- personalised content- PLEs deliver content that is personalised for the user, based on an understanding of its goals and previous knowledge;

- personalised sequencing- PLEs also adapt teaching materials by corresponding domain ontologies with dynamically developing user models;

- adaptative assessment- systems may choose questions for the learner at the boundary of its understanding;

- feedback agents- PLEs agents that observe student behaviour can attempt to present feedback and links to appropriate assisting materials;

- recommender agents- PLEs could recommend alternative resources based on user searching and study patterns;

- annotation tools- possible annotations that users create about themselves;

- search engines- when resources have been semantically enriched, then search engines can be much more powerful;

- analytical tools- tools that produce, store and analyse data from a range of sources.

The most fruitful contribution to understanding the possible categorization of the "knowledgeable files" is given by Burger and Westenthaler (2006a, b), which provides four dimensions that allow the recognition of content and knowledge combinations:

- knowledge must be encoded using a formal language;

- interoperability especially for cross domain aspects;

- different interpretations of content objects;

- clear definition of possible relations between content and knowledge.

Despite this positive contribution, some criticism may be made of the arguments of these authors:

- knowledge it not necessarily encoded, nor is it always characterized by formal language. For example, tacit knowledge or informal learning allowed by social networks;

- interoperability is not always observable in learning environments;

- it seems difficult for the e-learning agents, namely the IT managers, to understand all the possible relations between content and knowledge.

\section{Conclusion}

Given our research questions, as well as the ideas under debate throughout this paper, it is important to acknowledge some important claims:

- in spite of being a philosophical discussion our research question demonstrates a practical problem;
- e-learning main stream literature seems to assume that technological pedagogic content knowledge responds in a satisfactory way to the challenges, or disregards the discussion;

- the evolution of E-Learning Management Systems, namely PLEs, SS, LCMS will enhance the quandary, given their technological and non-technological features;

- the evolution of knowledge and content dimensions as semantics demonstrate, may give rise to a whole new set of questions;

However, we argue the following definitions for knowledge and content in an e-learning project: knowledge is dependent on conceptual skills and cognitive abilities, through action-oriented and systematic tasks in contextual practices, or through social interaction. Content refers to the encoded "unprocessed material" which succeeds in achieving the objectives that the content creator has set for it. Therefore, content is no longer measured by the personal content creator or audience opinion, but rather by the fulfilment of end goals through the following characteristics:

- thought-provoking- it should present new ideas or offer a critical and new look at ideas or assumptions commonly held by others;

- well researched- should provide multiple linkages to related discussions;

should add value- because it means time investment; unique- innovative content concerning research fields draws the attention of the audience;

- comprehensive- comprehensive content may outshine others "content providers" regarding the same theme;

- highly interactive- a piece of content can come not only in the form of written text but also in multimedia;

- ethical- anti-plagiarism design and structure is required.

Acknowledgments The authors of this paper would like to recognize the tremendous effort of Dr. Bernd Stahl, Ms. Mary Prior and Professor Simon Rogerson regarding their support and guidance throughout their $\mathrm{PhD}$ projects, and also to be grateful to all that have made comments and suggestions during ETHICOMP 2008.

\section{References}

Abazi-Bexheti, L. (2008). Development of a learning content management system. International Journal of Systems Applications, Engineering \& Development, 1(2), 1-5.

Akgun, A. E., Lynn, G. S., \& Byrne, J. C. (2003). Organizational learning: a sociocognitive framework. Human Relations, 56(7), 39-868.

Alavi, M. (ed). (1997). KPMG peat Marwick U.S.: one giant brain. Boston: Harvard Business School Case Publishing.

Alavi, M., \& Leidner, D. E. (2001). Review: knowledge management and knowledge management systems: conceptual foundations and research issues. MIS Quarterly, 25(1), 107-136. 
Alter, S. (1996). Information systems: a management perspective. Thousand Oaks: Benjamin/Cummings.

Amaral, L. A., \& Leal, D. (2004). From classroom teaching to elearning: the way for a strong definition. Braga: Universidade do Minho.

Anderson, T. (2004). Towards a theory of online learning. In T. Anderson \& F. Elloumi (Eds.), Theory and practice of online learning (pp. 33-60). Atabasca: Atabasca University.

Antilla, J. (ed). (2001). Dokumenttien hallinta. Helsinki: Oy Edita Ab.

Askew, M. (2007). Scaffolding revisited: from tool for result to tooland-result. In J. H. Woo, H. C. Lew, K. S. Park \& D. Y. Seo (Eds.), Proceedings of the 31th conference of the international group for the psychology of mathematics education (pp. 33-40). Seoul: PME.

Awad, E. M., \& Ghaziri, H. M. (2004). Knowledge management. Thousand Oaks: Prentice Hall.

Baird, L., Henderson, J. C., \& Watts, S. (1997). Learning from action: an analysis for the center of army lessons learned. Human Resource Management, 36(4), 385-396.

Ball, D. L., \& McDiarmid, G. W. (1990). The subject matter preparation of teachers. In R. Houston (Ed.), Handbook of Research on Teacher Education (pp. 437-449). New York: Macmillan.

Bergstedt, S., Wiegreffe, S., Wittmann, J., \& Moller, D. (2003). Content management systems and e-learning systems: a symbiosis? In D. G. Sampson, M. Spector, V. Devedzic \& Kinshuk (Eds.), Proceedings ICALT 2003 (155-159). Athens: IEEE Computer Society.

Bongalos, Y. Q., Bulaon, D. R., de Celedonio, L. P., de Guzman, A. B., \& Ogarte, C. J. (2006). University teachers' experiences in courseware development. British Journal of Educational Technology, 37(5), 695-704.

Brody, R. G., Kowalczyk, T. K., \& Coulter, J. M. (2003). The effect of a computerized decision aid on the development of knowledge. Journal of Business and Psychology, 18(2), 157-174.

Brooks, C., Pasenar, R., \& Greer, J. (2006). Social awareness in the iHelp courses learning content management system. In W. Nejdl \& K. Tochtermann (Eds.), EC-TEL 2006 (pp. 34-44). Berlin: Springer-Verlag.

Bucat, R. (2004). Implications of chemistry education research for teaching practice: pedagogical content knowledge as a way forward. Chemistry Education: Research and Practice, 5(3), 215-218.

Buckland, M. K. (1991). Information as a thing. Journal of the American Society for Information Science, 428(5), 351-360.

Budin, G. (2002). Global content management-challenges and opportunities for creating and using digital translation resources. Resource document. University of Vienna. http://www.ifi.unizh. $\mathrm{ch} / \mathrm{cl} /$ yuste/postworkshop/repository/gbudin.pdf. Accessed 17.01.2009.

Burger, T., \& Westenthaler, R. (2006a). Why the combination of content and knowledge matters. research technical report. Salzburg: University of Innsbruck.

Burger, T., \& Westenthaler, R. (2006b). Mind the gap-requirements for the combination of content and knowledge. In Y. S. Avrithis, Y. Kompatsiaris, S. Staab \& N. E. O'Connor (Eds.), Proceedings of SMAT 2006 (pp. 1-2). Athens: CEUR-WS.

Bynum, T. W., \& Rogerson, S. (eds). (2004). Computer ethics and professional responsibility. Oxford: Blackwell.

Carvalho, J. A., \& Amaral, L. A. (1993). Matriz de actividades : um enquadramento conceptual para as actividades de planeamento e desenvolvimento dos sistemas de informação. Revista da Associação Portuguesa de Sistemas de Informação, 1, 37-48.

Cash, J. I., McFarlan, F. W., \& McKenney, J. L. (1992). Corporate information systems management-the issues facing senior executives. Homewood: Business One Irwin.
Cavin, R. M. (2008). Developing technological pedagogical content knowledge in pre-service teachers through microteaching lesson study. In K. McFerrin, R. Webber, R. Carlsen \& D. A. Willis (Eds.), Proceedings of Society for Information Technology and Teacher Education International Conference 2008 (pp. 52145220). Chesapeake: AACE.

Chatti, M. A., Jarke, M., \& Frosch-Wilke, D. (2007). The future of elearning: a shift to knowledge networking and social software. International Journal Knowledge and Learning, 3(4/5), 404-420.

Clifford, J. (ed). (1988). The predicament of culture. Cambridge: Harvard University Press.

Content Management Junction (2008). Understanding content management in e-learning perspective. Resource document. Content Management Junction. http://www.content-management-junc tion.com/cm-elearning.html. Accessed 17.01.2009.

Crump, N. \& Costea, B. (2003). Pedagogical objects in management education: a cultural historical critique. Working paper. Lancaster University Management School. http://www.lums.co.uk/publica tions. Accessed 15.01.2009.

Dalsgaard, C. (2006). Social software: e-learning beyond learning management systems. Resource document. European Journal of Open, Distance Learning. http://www.eurodl.org/materials/con trib/2006/Christian_Dalsgaard.htm. Accessed 17.01.2009.

de Byl, P. B. (2007). A web 2.0/web 3D hybrid platform for engaging in e-learning environments. Turkish Online Journal of Distance Education, 8(3), 108-127.

Demetrios, G. S., Lytras, M. D., Wagner, G. \& Diaz, P. (Eds.) (2004). Ontologies and the semantic web for e-learning. Special Issue of the IEEE IFETS Journal of Educational Technology and Society, $7(4), 26-28$.

Dilnutt, R. (2002). Knowledge management in practice: three contemporary case studies. International Journal of Accounting Information Systems, 3(2), 75-82.

Efimova, L., \& Swaak, J. (2002). KM and (e)-learning: towards an integral approach? In S. Gherardi \& D. Nicollini (Eds.), Proceedings of the 2nd EKMF knowledge management summer school (pp. 63-69). Sophia: Knowledge Board.

Eining, M. M., \& Dorr, P. B. (1991). The impact of expert system usage on experiential learning in an auditing setting. Journal of Information Systems, 5(2), 1-15.

Eisenhardt, K. M., \& Martin, J. A. (2000). Dynamic capabilities: what are they? The Strategic Management Journal, 21(10/11), 1105-1121.

Foskett, A. C. (1977). The subject approach to information. Hamden: Linnet Books.

Fraser, J. (2006). More PLE questions. Resource document. EdTechUK. http://fraser.typepad.com/edtechuk/2006/10/more_ple_ questi.html. Accessed 17.01.2009.

Furstenberg, G., Levet, S., English, K. A., \& Maillet, K. (2001). Giving a virtual voice to the silent language of culture: the Cultura project. Language, Learning \& Technology, 5(1), 55-102.

Gartner Group. (2002). The 2002 knowledge management hype cycle. Stamford: Gartner Group.

Gergen, K. J. (1995). Social construction and the educational process. In L. P. Steffe, J. E. Gale \& J. Gale (Eds.), Constructivism in education (pp. 17-39). Hillsdale: Lawrence Erlbaum.

Grover, V., \& Davenport, T. H. (2001). General perspectives on knowledge management: fostering a research agenda. Journal of Management Information Systems, 18(1), 5-23.

Gudmundsdottir, S. (1990). Values and pedagogic content knowledge. Journal of Teacher Education, 41(3), 44-52.

Hall, B. (2003). New Technology Definitions. Glossary. Brandon Hall Research. http://www.brandonhall.com/public/glossary/index. htm. Accessed 15.01.2009.

Hall, D. J., \& Paradice, D. B. (2005). Philosophical foundations for a learning-oriented knowledge management system for decision support. Decision Support Systems, 39(3), 445-461. 
Hall, D. J., Paradice, D. B., \& Courtney, J. F. (2003). Building a theoretical foundation for a learning-oriented knowledge management system. Journal of Information Technology Theory and Application, 5(2), 63-89.

Himma, K. E. (2005). Information and intellectual property protection: evaluating the claim that information should be free. Resource document. Berkeley Center for Law and Technology. http:// repositories.cdlib.org/bclt/lts/12. Accessed 17.01.2009.

Hofstede, G. J. (1986). Cultural differences in teaching and learning. International Journal of Intercultural Relations, 10(3), 301-320.

Horton, W. K. (ed). (2000). Designing web-based training: how to teach anyone, anywhere, anytime. New York: Wiley Computer Publications.

HP (2008). Content transformation. HP. Resource document. http:// www.hpl.hp.com/research/content.html. Accessed 17.01.2009.

In Time (2001). Technology. Resource document. University of Northern Iowa. http://www.intime.uni.edu/model/technology/ tech.html. Accessed 17.01.2009.

Inglis, A. (2003). Will knowledge management technologies be behind the next generation of e-learning systems? Resource document. Open \& Distance Learning Association of Australia. http://www.odlaa.org/publications/2003Proceedings/pdfs/inglis. pdf. Accessed 17.01.2009.

Jefferies, P., \& Stahl, B. C. (2005). Some ethical considerations regarding the relationship of e-learning and pedagogy. In G. Collste, S. O. Hansson, S. Rogerson \& T. W. Bynum (Eds.), ETHICOMP 2005. Linkoping: Linkoping University.

Jenkins, M., Browne, T. \& Walker, R. (2005). VLE Surveys: a longitudinal perspective between March 2001, March 2003 and March 2005 for higher education in the United Kingdom. Survey. UCISA. http://www.ucisa.ac.uk/groups/tlig/vle/vle survey 2005. pdf. Accessed 16.01.2009.

Jervis, M. D. (2008). Integrating physical and digital workspaces. In J. Holland, A. Nicholas \& D. Brignoli (Eds.), NZCSRSC 2008 (pp. 222-225). Christchurch: University of Canterbury.

JISC (2000). Managed Learning Environments (MLEs) in further education: progress report. Circular 7/00. Joint Information Systems Committee. http://www.jisc.ac.uk/news/stories/2000/07/ circular700. Accessed 16.01.2009.

Jonassen, D. H., \& Carr, C. S. (2000). Mindtools: affording multiple knowledge representations for learning. In S. P. Lajoie (Ed.), Computers as cognitive tools (pp. 165-196). Mahwah: Lawrence Earlbaum Associates.

Jonassen, D. H., \& Reeves, T. C. (1996). Learning with technology: using computers as cognitive tools. In D. H. Jonassen (Ed.), Handbook of research for educational communications and technology (pp. 693-719). New York: Macmillan.

Jowett, B. (1899). Protagoras: dialogues of Plato. Michigan: The Colonial.

Jurubescu, T. (2008). The learning content management system. Revista Informatica Economicã, 4(48), 91-94.

Kanuka, H. (2006). Instructional design and e-learning: a discussion of pedagogical content knowledge as a missing construct. Paper. The e-Journal of Instructional Science and Technology, 9(2). http://www.usq.edu.au/electpub/e-jist/docs/vol9 no2/papers/ full_papers/kanuka.htm. Accessed 17.01.2009.

Karrer, T. (2007). Understanding e-Learning 2.0. Resource document. ASTD. http://www.astd.org/LC/2007/0707_karrer.htm. Accessed 17.01.2009

Keegan, D. (1988). On defining distance education. In D. K. Stewart, D. Keegan \& B. Holmberg (Eds.), Distance education: international perspectives (pp. 6-33). London/New York: Routledge.

Kendall, J. S. \& Marzano, R. J. (1997). Content knowledge: a compendium of standards and benchmarks for K-12 education. Resource document. Mid-continent Research for Education and
Learning. http://www.mcrel.org/standards-benchmarks. Accessed 15.01.2009.

King, W. R. (2005). Communications and Information processing as a critical success factor in the effective knowledge organization. International Journal of Business Information Systems, 1(1/2), $31-52$.

King, W. R., Marks, P. V., \& McCoy, S. (2002). The most important issues in knowledge management. Communications of the ACM, 45(9), 93-97.

Kohlberg, L. (ed). (1981). Essays on moral development. San Francisco: Harper \& Row.

Koppelman, H. (2008). Pedagogical content knowledge and educational cases in computer science: an exploration. Resource document. Informing Science. http://proceedings.informingscience.org/ InSITE2008/InSITE08p125-133Koppe1450.pdf. Accessed 17.01.2009.

Kornai, A. (2008). On the proper definition of information. In T. W. Bynum, M. C. Calzarossa, I. D. Lotto \& S. Rogerson (Eds.), ETHICOMP 2008 (pp. 488-495). Mantova: University of Pavia.

KPMG. (2000). The knowledge management research report 2000. London: KPMG International.

Kuhn, T. S. (1970). Reflections on my critics. In I. Lakatos \& A. Musgrave (Eds.), Criticism and the growth of knowledge (pp. 231-278). Cambridge: Cambridge University Press.

Lassila, A., \& Poyry, P. L. (2007). Online education and learning management systems from service-centered perspective source. In V. Koskov (Ed.), Proceedings of IASTED International Conference Web-Based Education (pp. 322-330). Anaheim: ACTA Press.

Learning Circuits. (2002). Field guide to learning management systems. Resource document. Learning Circuits. http://www. learningcircuits.org/NR/rdonlyres/BFEC9F41-66C2-42EFBE9D-E4FA0D3CE1CE/7304/LMS fieldguide1.pdf. Accessed 17.01.2009.

Leech, S. A., \& Sutton, S. G. (2002). Knowledge management issues in practice: opportunities for research. International Journal of Accounting Information Systems, 3(2), 69-74.

Lytras, D. M., \& Sicilia, M. A. (2005). Modelling the organizational aspects of learning objects in semantic web approaches to information systems. Interdisciplinary Journal of Knowledge and Learning Objects, 1, 255-267.

Malhotra, Y. (2001). Expert systems for knowledge management: crossing the chasm between information processing and sense making. Expert Systems in Applications, 20(1), 7-16.

Markus, M. L., Majchrzak, A., \& Gasser, L. (2002). A design theory for systems that support emergent knowledge processus. MIS Quarterly, 3(3), 179-212.

Martin, E. R., \& Webb, D. (2001). Is e-learning good learning? In B. Brook \& A. Gilding (Eds.), The ethics and equity of e-learning in higher education (pp. 49-60). Melbourne: Victoria University.

Marwick, A. D. (2001). Knowledge management technology. IBM Systems Journal, 40(4), 814-830.

Mascha, M. F. (2001). The effect of task complexity and expert system type on the acquisition of procedural knowledge: some new evidence. International Journal of Accounting Information Systems, 2(2), 103-124.

Mason, J. (2005). From e-learning to e-knowledge. In M. Rao (Ed.), Knowledge management tools and techniques (pp. 320-328). London: Elsevier Butterworth-Heinemann.

McKeever, S. (2003). Understanding web content management systems: evolution, lifecycle and market. Industrial Management \& Data Systems, 103(9), 686-692.

McRobb, S., Jefferies, P., \& Stahl, B. C. (2007). Exploring the relationships between pedagogy, ethics \& technology: building a framework for strategy development. Technology, Pedagogy \& Education, 16(1), 111-126. 
Mihalca, R., Uță, A., Andreescu, A., \& Întorsureanu, J. (2008). Knowledge management in e-learning systems. Revista Informatica Economică, 2(46), 60-65.

Millard, D. E., Tao, F., Doody, K., Woukeu, A., \& Davis, H. C. (2006). The knowledge life cycle for e-learning. International Journal of Continuing Engineering Education and Life-Long Learning, 16(1/2), 110-121.

Mulhall, P., Berry, A. \& Loughran, J. (2003). Frameworks for representing science teachers' pedagogical content knowledge. Resource document. Asia-Pacific Forum on Science Learning and Teaching. The Hong Kong Institute of Education. http:// www.ied.edu.hk/apfslt/v4_issue $2 /$ mulhall/index.htm. Accessed 17.01.2009.

Nagi, K. (2006). Solving ethical issues in e-learning. Special Issue of the International Journal of the Computer, the Internet and Management, 14(SP1), 7.1-7.6.

Nonaka, I. (1994). A dynamic theory of organizational knowledge creation. Organization Science, 1(5), 14-37.

Nonaka, I. (2002). A dynamic theory of organizational knowledge creation. Organizational Journal of Strategic Information Systems, 11(2), 85-107.

Nonaka, I., \& Takeuchi, H. (1995). The knowledge creating-company: how Japanese companies create the dynamics of innovation. New York: Oxford University Press.

Nonaka, I., Reinmoller, P., \& Toyama, R. (2001). Integrated information technology systems for knowledge creation. In M. Dierkes, A. B. Berthoin, J. Child \& I. Nonaka (Eds.), Handbook of organizational learning and knowledge (pp. 827-848). Oxford: Oxford University Press.

OECD. (2008). Digital content. Resource document. Organisation for Economic Co-operation and Development. http://www.oecd.org/ document $/ 62 / 0,3343$,en_2649_34223_32160190_1_1_1_1,00. html. Accessed 16.01.2009.

Online Etymology Dictionary. (2001). Content. Resource document. Online Etymology Dictionary. http://www.etymonline.com/index. php?search $=$ content\&searchmode $=$ none. Accessed 17.01.2009.

Ornstein, A. C., Thomas, J. L., \& Lasley, T. J. (eds). (2000). Strategies for effective teaching. New York: McGraw-Hill.

Oxford Dictionary. (2008). Oxford english dictionary. Oxford: Oxford University Press.

Phillips, J. T. (2000). Will KM alter information managers' roles? Information Management Journal, 34(3), 58-59.

Podoleanu, M. C. (2005). The learning content management system. Economy Informatics, 1(4), 67-71.

Poston, R. S., \& Speier, C. (2005). Effective use of knowledge management systems: a process model of content ratings and credibility indicators. MIS Quarterly, 29(2), 221-244.

Prusack, L. (2001). Where did knowledge management come from? IBM Systems Journal, 40(4), 1002-1007.

Reeves, T. C. (1999). A research agenda for interactive learning in the new millennium. In B. A. Collis \& R. Oliver (Eds.), Proceedings of world conference on educational multimedia, hypermedia and telecommunications 1999 (pp. 15-20). Chesapeake: AACE.

Reynolds, M. (1997). Learning styles: a critique. Management Learning, 28(2), 115-133.

Richards, C. (2004). From old to new learning: global dilemmas, exemplary Asian contexts, and ICT as a key to cultural change in education. Globalization, Societies and Education, 2(3), 337353.

Richter, C., Allert, H., \& Nejdl, W. (2005). Minimal activity plans: artifacts for self-organized learning within organizations. In E. M. Ras, M. Memmel \& S. Weibelzahl (Eds.), First workshop on learner-oriented knowledge management \& KM-oriented ELearning (pp. 166-169). Kaiserslautern: Springer Verlag.
Robertson, J. (2002). How to evaluate a content management system. Resource document. Intranet Journal. http://www.intranetjournal. com/articles/200208/pse_08_19_02c.html. Accessed 16.01.2009.

Ronchetti, M., \& Saini, P. S. (2004). Knowledge management in an elearning system. In L. C-K, E. S. Kinshuk, D. G. Sampson, I. Aedo, L. Uden \& E. Kahkonen (Eds.), Proceedings of ICALT'04 (pp. 365-369). Joensuu: IEEE International.

Rose, J. M. (2005). Decision aids and experiential learning. Behavioural Research in Accounting, 17(1), 175-189.

Rose, J. M., \& Wolfe, C. J. (2000). The effects of system design alternatives on the acquisition of tax knowledge from a computerized tax decision aid. Accounting, Organizations and Society, 25(3), 285-306.

Rowan, B., Schilling, S. G., Ball, D. L., Miller, R., Atkins-Burnett, S., et al. (2001). Measuring teachers' pedagogical content knowledge in surveys: an exploratory study. Working paper. Michigan University. http://www.sii.soe.umich.edu/documents/pck\%20final\%20report $\%$ 20revised\%20BR100901.pdf. Accessed 17.01.2009.

Rowley, J. (1998). What is information? Information Services \& Use, 18(4), 243-254.

Sallis, E., \& Jones, G. (eds). (2002). Knowledge management in education: enhancing learning \& education. London: Kogan Page.

Sarah, R. \& Haslett, T. (2003). A feedback model of knowledgecreation using conversation-based learning. Working paper. Monash University. http://www.buseco.monash.edu.au/mgt/re search/working-papers/2003/wp72-03.pdf. Accessed 14.01.2009.

Schulmeister, B. R. (ed). (2003). Lernplattformen für das virtuelle lernen, evaluation und didaktik. Munique: Oldenburgo.

Sehring, H. W., Bossung, S., \& Schmidt, J. W. (2006). Content is capricious: a case for dynamic system generation. In Y. Manolopoulos, J. Pokorný \& T. K. Sellis (Eds.), ADBIS 2006 (pp. 430-445). Thessaloniki: Springer-Verlag.

Shaw, S. (2007). Dynamic content: connecting performance and learning. Resource document. ASTD. http://www.astd.org/LC/ 2007/0807_shaw.htm. Accessed 15.01.2009.

Shaw, S. (2008). Collaboration in the world of ISD. Resource document. ASTD. http://www.astd.org/LC/2008/0108_shaw. htm. Accessed 15.01.2009.

Sheridan, W. (2008). How to think like a knowledge worker. United Nations Public Administration. Resource document. http://unpan1. un.org/intradoc/groups/public/documents/unpan/unpan031277.pdf. Accessed 17.01.2009.

Shulman, L. S. (1988). Disciplines of inquiry in education: an overview. In R. M. Jaeger (Ed.), Complementary methods for research in education (pp. 3-17). Washington: AERA.

Siemens, G. (2004). Learning management systems: the wrong place to start learning. Resource document. Elearnspace. http://www. elearnspace.org/Articles/lms.htm. Accessed 17.01.2009.

Sigrén, P., \& Holmqvist, H. (2005). Syntes och analys av tidigare kravspecifikationer för upphandling av lms inom den svenska högskolan 2000-2004. Härnösand: Myndigheten för Sveriges nätuniversitet.

Silva, N. S. A. (2007). An investigation on the impact of culture and ethics on the implementation of e-university. MPhil/PhD transfer document. Leicester: De Montfort University.

Small, G. W., \& Vorgan, G. (2008). iBrain: surviving the technological alteration of the modern mind. New York: Harper Collins.

Smedley, G. A., \& Sutton, S. G. (2004). Explanation provision in knowledge-based systems: a theory-driven approach for knowledge transfer designs. Journal of Emerging Technologies in Accounting, 1(1), 41-61.

Snowden, D. J. (2000). The paradox of story. Journal of Scenario and Strategy Planning, 1(5), 16-20. 
Stacey, P. (2001). E-learning value chain and market map. Resource document. T-Net British Columbia. http://www.bctechnology. com/statics/bcelearning.swf. Accessed 15.01.2009.

Stahl, B. C. (2002a). Ethical issues in e-teaching-a theoretical framework. In G. King, M. Ross, G. Staples \& T. Twomey (Eds.), Proceedings of INSPIRE VII, quality in learning and delivery techniques (pp. 135-148). Limerick: The British Computer Society.

Stahl, B. C. (2002b). Ethics and e-teaching: the students' perspective. Communications of the IIMA, 2(3), 51-62.

Stahl, B. C. (2005). E-voting: an example of collaborative e-teaching and e-learning. Journal of Interactive Technology \& Smart Education, 2(1), 19-30.

Stahl, B. C. (2007). Privacy and security as ideology. IEEE Technology and Society Magazine, 26(1), 35-45.

Standards Australia. (2003). Interim Australian Standard- Knowledge Management. Resource document. Standards Australia Limited. http://www.standards.com.au. Accessed 14.01.2009.

Svarre, K. (2006). What is content management system? Resource document. SOA. http://searchsoa.techtarget.com/sDefinition $/ 0$, sid26_gci508916,00.html. Accessed 16.01.2009.

The Free Dictionary. (2008). Content. Resource document. The Free Dictionary. http://freedictionary.org. Accessed 17.01.2009.

Turban, E., King, D., Lee, J. K., \& Viehland, D. (eds). (2006). Electronic commerce: a managerial perspective. Thousand Oaks: Prentice Hall.

van Harmelen, M. (2006). Personal learning environments. Resource document. University of Manchester. http://octette.cs.man.ac.uk/ jitt/index.php/Personal_Learning_Environments. Accessed 17.01.2009.

Weller, M. J. (2007). Virtual learning environments: using, choosing and developing your VLE. London: Routledge.

Wickramasinghe, N., \& Mills, G. L. (2002). Integrating e-commerce and knowledge management-what does the Kaiser experience really tell us. International Journal of Accounting Information Systems, 3(2), 83-98.

Wild, F., Modritscher, F. \& Sigurdason, S. (2008). Designing for change: mash-up personal learning environments. Resource document. E-learning Papers. http://www.elearningeuropa.info/ files/media/media15972.pdf. Accessed 17.01.2009.

Wilkoff, N., Walker J., Root, N.L. \& Dalton J.P. (2001). What's next for content management? Resource document. Forrester Research. http://www.documentum.com/news/reviews/forrester_cm.htm. Accessed 17.01.2009.

Williams, M. C. (2002). A conversation regarding ethics in information systems educational research. In A. Salehnia (Ed.), Ethical Issues of Information Systems (pp. 164-176). Hershey: IRM Press.

Wilson, S. M., Schulman, L. S., \& Richért, A. E. (1987). 150 different ways of knowing: representations of knowledge in teaching. In J. Calderhead (Ed.), Exploring teachers' thinking (pp. 104-124). London: Cassell Education.

Winter, M. (2006). Learning Management Systems in the workplace: a research report. Research report. Tertiary Accord of New Zealand. http://www.tanz.ac.nz/pdf/LMS_Final.pdf. Accessed 17.01.2009.

Wright, K. (2005). Personal knowledge management: supporting individual knowledge worker performance. Knowledge Management, Research and Practice, 3(3), 156-165.

Yordanova, K. (2008). Integrated solution for learning content management systems development. In V. Uskov (Ed.), WebBased Education 2008 (pp. 125-128). Innsbruck: ACTA.

Zollo, M., \& Winter, S. G. (2002). Deliberate learning and the evolution of dynamic capabilities. Organization Science, 13(3), $339-351$.

Gonçalo Jorge Morais Costa is doing $\mathrm{PhD}$ in Knowledge Management and Ethics in De Montfort University with supervision of Ms. Mary Prior and Professor Simon Rogerson. Plus, he holds a Degree in Economics, a Pos-Degree in E-Business and IT, and a Masters in Management. He is also a lecturer in several Portuguese universities and his current research areas are all the major appliances regarding IT and ethics as demonstrated throughout his published and presented work in several journals and conferences.

Nuno Sotero Alves Silva is doing $\mathrm{PhD}$ in Computer Ethics and Education in De Montfort University with supervision of Professor Simon Rogerson and Dr. Bernd Stahl. Plus, he holds a Degree in Computer Science Engineering and a Pos-Degree in E-Business and IT. He is also a lecturer and IT Manager in Lusíada University of Lisbon, Portugal. His current research areas are e-learning, computer happiness and bionanotechnology bounded to ethics. 